\title{
Microbiology
}

Chemotherapy

Chemotherapy 2012;58:475-481

DOI: $10.1159 / 000346352$
Received: August 27, 2012

Accepted after revision: December 3, 2012

Published online: March 21, 2013

\section{One-Year Surveillance of ESKAPE Pathogens in an Intensive Care Unit of Monterrey, Mexico}

\author{
Jorge Martín Llaca-Díaz ${ }^{a}$ Soraya Mendoza-Olazarán ${ }^{b} \quad$ Adrian Camacho-Ortiz $^{c}$ \\ Samantha Flores ${ }^{d}$ Elvira Garza-González ${ }^{a}$ b \\ a Departamento de Patología Clínica, b Servicio de Gastroenterología and 'Servicio de Infectología, Hospital \\ Universitario Dr. José Eleuterio González and d Departamento de Microbiología, Facultad de Medicina, Universidad \\ Autónoma de Nuevo León, Monterrey, México
}

\section{Key Words}

Extended spectrum $\beta$-lactamases · Multidrug resistance .

Intensive care unit · Vancomycin

\begin{abstract}
Background: Bacterial species from the ESKAPE group (i.e. Enterococcus faecium, Staphylococcus aureus, Klebsiella pneumoniae, Acinetobacter baumannii, Pseudomonas aeruginosa and Enterobacter species) are frequently resistant to antibiotics. The purpose of this study was to monitor the incidence of ESKAPE pathogens at the intensive care unit (ICU) of a tertiary care hospital in Monterrey, Mexico. Methods: All clinically relevant organisms isolated from June 2011 to June 2012 were included. Identification and susceptibility testing was performed using panels from Sensititre. Resistance to oxacillin, for S. aureus, and the production of extended spectrum $\beta$-lactamases (ESBLs), for $K$. pneumonia, were determined as defined by the Clinical Laboratory Standards Institute. Also, the presence of vanA and $v a n B$ genes was determined in $E$. faecium vancomycin (VAN)-resistant isolates. Results: The majority of pathogens (64.5\%) isolated in the ICU unit were from the ESKAPE group. The organisms most frequently isolated were A. bau-
\end{abstract}

\section{KARGER}

E-Mail karger@karger.com

www.karger.com/che mannii (15.8\%) and $P$. aeruginosa (14.3\%). A high resistance to carbapenems was detected for A. baumannii (75.3\%) while $62 \%$ of $S$. aureus isolates were confirmed to be methicillin resistant. Of the $K$. pneumoniae isolates, $36.9 \%$ were ESBL producers. We detected three $E$. faecium VAN-resistant isolates, all of which contained the vanA gene. Conclusion: The presence of the ESKAPE group of pathogens is a major problem in the ICU setting. The results of this study support the implementation of special antimicrobial strategies to specifically target these microorganisms.

Copyright $\odot 2013$ S. Karger AG, Basel

\section{Introduction}

Antimicrobial resistance among both Gram-positive and Gram-negative bacteria has been on the rise in the past few years [1-3]. The presence of multidrug-resistant (MDR) pathogens has become a cause for serious concern with regard to nosocomial infections. In fact, the World Health Organization has recently recognized antimicrobial resistance as one of the three most important human health concerns [4]. The most common and threatening MDR pathogens have been grouped together under the
(C) 2013 S. Karger AG Basel

0009-3157/13/0586-0475\$38.00/0 
acronym 'ESKAPE,' which stands for Enterococcus faecium, Staphylococcus aureus, Klebsiella pneumoniae, Acinetobacter baumannii, Pseudomonas aeruginosa and Enterobacter spp. [5-8].

Three decades ago, A. baumannii was sensitive to most antibiotics, but today it is exceptionally resistant to most antibiotics [9], with carbapenem resistance being greater than $50 \%$ in some countries [10]. Recently, data from Monterrey, Mexico, reported a meropenem (MEM) resistance of $69 \%$ [11]. A major factor contributing to antibiotic resistance is the production of extended spectrum $\beta$-lactamases (ESBLs) by the Enterobacteriaceae species, particularly $K$. pneumoniae [12].The dissemination of ESBL-producing Gram-negative pathogens in hospitals is an emerging global problem that deserves special consideration $[13,14]$.

Another important species of the ESKAPE group is $S$. aureus, particularly methicillin-resistant $S$. aureus (MRSA), which has an incidence and prevalence that continues to increase rapidly in many regions of the world. The mortality rate associated with invasive MRSA infections is estimated at approximately $20 \%$ [15] and bloodstream infections caused by this bacterial species are associated with a high mortality rate and length of hospital stay [16]. Finally, isolates of Enterococcus faecalis and E. faecium are the third- to fourth-most prevalent nosocomial pathogen worldwide. Acquired resistance, particularly to glycopeptides, is reported for a number of these isolates, thus limiting the number of therapeutic options $[17,18]$.

Global and regional surveillance of ESKAPE pathogens is fundamental to control the infections caused by these bacterial species [19]. The purpose of this study was to monitor the incidence of ESKAPE pathogens in an intensive care unit (ICU) of a tertiary care hospital in Monterrey, Mexico.

\section{Methods}

\section{Setting and Clinical Isolates}

This study was conducted at the Dr. José Eleuterio Gonzalez University Hospital, a teaching hospital in Monterrey, Nuevo Leon, Mexico. This hospital provides tertiary medical care in seven wards, including three ICUs spanning pediatric, medical and surgical units. This study was performed in the medical and surgical ICUs with a combined 20-bed area. During the study period (from 3 June 2011 to 3 June 2012), 1,692 clinical isolates were obtained from both ICUs. The first isolate of a particular species per patient, irrespective of the body site, was recorded. Only patient specimens taken for diagnostic purposes were included.
Antimicrobial Susceptibility and Identification Assays

The species identification and susceptibility testing were performed using the broth microdilution method. Panels were obtained from Sensititre (TEK Diagnostic Systems Inc., Cleveland, Ohio, USA) and were used as described by the manufacturer. Antimicrobials tested against Gram-negative bacteria included: amikacin (AMK), aztreonam (AZT), cefotaxime (CTX), ceftazidime (CAZ), chloramphenicol (CHL), ciprofloxacin (CIP), gentamicin (GEN), imipenem (IPN), MEM, ticarcillin (TIC) and tobramycin (TOB). Antibiotics included against Gram-positive bacteria included clindamycin (CLI), erythromycin (ERY), high-concentration GEN (GEN500), linezolid (LNZ), oxacillin (OXA), penicillin (PEN), quinupristin/dalfopristin (QUD), teicoplanin (TEI), highconcentration streptomycin (ST1000), tetracycline (TET) and vancomycin (VAN). Antibiotics used against both Gram-positive and Gram-negative organisms included: amoxicillin-clavulanic acid (AMX), ampicillin (AMP), cefepime (FEP), ceftriaxone (CRO), cefuroxime (CXM), levofloxacin (LVX) and trimethoprim/ sulfamethoxazole (SXT).

Multidrug resistance was defined as having a resistance to three or more classes of antimicrobials. The class definitions used in this study were: penicillins (PEN), cephalosporins (FEP, CTX, CAZ, CRO, CXM), carbapenems (IPN, MEM), fluoroquinolones (LVX), aminoglycosides (AMK, GEN, TOB) and tetracyclines (TET). Assay control organisms and susceptibility breakpoints were those recommended by the Clinical Laboratory Standards Institute (CLSI) [20].

\section{ESBL Production and Detection of MRSA}

Presumptive ESBL producers were identified by determining the minimal inhibitory concentrations (MIC) for CAZ and CTX. The combination disk method, alone and in combination with inhibitory clavulanic acid, was used to confirm the expression of ESBLs. Both presumptive and confirmatory tests were performed following CLSI guidelines [20]. Additionally, the MIC of OXA was determined as recommended by the CLSI [20].

\section{Detection of the van Genes}

Genomic DNA of E. faecium VAN-resistant isolates was obtained by phenol chloroform and ethanol precipitation. PCR assays were performed as described previously [21]. Approximately 100 ng of DNA was added to a PCR mixture containing $10 \times$ PCR buffer, $0.2 \mathrm{mM}$ deoxyribonucleotide and $1 \mathrm{U}$ of Taq DNA polymerase (Bioline). Two different primer sets (one each for vanA and $v a n B$ ) were used in the assay. Amplification of DNA was performed with denaturation at $94^{\circ} \mathrm{C}$ for $2 \mathrm{~min}$, followed by 30 cycles of $1 \mathrm{~min}$ at $94^{\circ} \mathrm{C}, 1 \mathrm{~min}$ at $54^{\circ} \mathrm{C}$ and $1 \mathrm{~min}$ at $72^{\circ} \mathrm{C}$. Amplicons were analyzed by electrophoresis on $1 \%$ agarose gels.

\section{Results}

\section{Distribution of Species by Clinical Specimen}

A total of 1,692 clinical isolates were recovered from clinical specimens, which included respiratory, blood, urine, catheter and other sites (table 1). ESKAPE pathogens were identified in $64.5 \%(1,092 / 1,692)$ of isolates. Overall, the organisms most frequently isolated were 
Table 1. Distribution of ESKAPE pathogens and other species isolated from clinical specimens collected in the ICU of the José Eleuterio González University Hospital from June 2011 to June 2012

\begin{tabular}{lcccccc}
\hline Pathogen & Global & Respiratory & Blood & Urine & Catheter & Other \\
\hline ESKAPE group & & & & & & \\
$\quad$ A. baumannii & $268(15.8)$ & $168(18.8)$ & $42(13.6)$ & $10(5.7)$ & $22(13.8)$ & $26(17.2)$ \\
$\quad$ P. aeruginosa & $242(14.3)$ & $130(14.5)$ & $32(10.3)$ & $41(23.3)$ & $24(15)$ & $15(9.9)$ \\
$\quad$ S. aureus & $241(14.2)$ & $163(18.2)$ & $38(12.3)$ & $4(2.3)$ & $16(10)$ & $20(13.2)$ \\
K. pneumoniae & $192(11.3)$ & $113(12.6)$ & $23(7.4)$ & $18(10.2)$ & $24(15)$ & $14(9.3)$ \\
E. faecium & $35(2.1)$ & $9(1)$ & $8(2.6)$ & $11(6.3)$ & $1(0.6)$ & $6(4)$ \\
$\quad$ E. cloacae & $69(4.1)$ & $28(3.1)$ & $15(4.8)$ & $7(4)$ & $12(7.5)$ & $7(4.6)$ \\
E. aerogenes & $28(1.7)$ & $17(1.9)$ & $2(0.6)$ & $4(2.3)$ & $3(1.9)$ & $2(1.3)$ \\
Other species & $17(1)$ & $9(1)$ & - & $6(3.4)$ & - & $2(1.3)$ \\
\hline Enterobacter & & & & & $10(6.3)$ & $5(3.3)$ \\
$\quad$ CoNS & $146(8.6)$ & $37(4.1)$ & $88(28.4)$ & $6(3.4)$ & $16(13.1)$ & $16(10.6)$ \\
E. faecalis & $121(7.2)$ & $42(4.7)$ & $13(4.2)$ & $29(16.5)$ & $21(1)$ \\
E. coli & $90(5.3)$ & $36(4)$ & $9(2.9)$ & $17(9.7)$ & $10(6.3)$ & $18(1.9)$ \\
Other species & $243(14.4)$ & $143(16)$ & $40(12.9)$ & $23(13.1)$ & $17(10.6)$ & $20(13.2)$ \\
\hline Total & $1,692(100)$ & $895(100)$ & $310(100)$ & $176(100)$ & $160(100)$ & $151(100)$ \\
\hline
\end{tabular}

Figures in parentheses are percentage. CoNS = Coagulase-negative staphylococci.

A. baumannii (15.8\%), P. aeruginosa (14.3\%), S. aureus (14.2) and K. pneumoniae (11.3\%). A. baumannii and S. aureus were most frequently isolated from respiratory specimens (18.8 and 18.3\%, respectively). From blood specimens, the most frequently isolated species were $A$. baumannii and S. aureus (13.6 and $12.3 \%$, respectively), while $P$. aeruginosa was the most common isolate in urine (23.3\%). In catheters, K. pneumoniae and P. aeruginosa were the predominant species (15\% for both species).

\section{Antibiotic Resistance}

Data detailing the $\mathrm{MIC}_{50}, \mathrm{MIC}_{90}$ and percentages of antimicrobial resistance for each of the ESKAPE pathogens, as well as for a few other frequent species, are presented in tables 2 and 3 . In general, a high prevalence of drug resistance was detected. For A. baumannii, the percentages of resistance were higher than $72 \%$ for all antimicrobial agents evaluated, except for FEP (23.2\%). For $K$. pneumoniae, 3 out of the 16 antimicrobial agents evaluated showed resistance percentages higher than $54 \%$.

From all isolates, $86.2 \%(231 / 268)$ of $A$. baumannii isolates were MDR, as were $100 \%$ (114/114) of Enterobacter spp., $59.4 \%(114 / 192)$ of K. pneumoniae and $28.9 \%$ (70/242) of $P$. aeruginosa. Furthermore, 20.9\% (56/268) of $A$. baumannii isolates were found to be extensively drug resistant because they showed resistance to all 13 antimicrobial agents evaluated. Among the species isolated that were not part of the ESKAPE group, $76.7 \%$ (69/90) of E. coli were MDR.

\section{Prevalence of ESBL-Positive Enterobacteriaceae and MRSA}

For K. pneumoniae isolates $(\mathrm{n}=192)$, 89 were determined to be ESBL producers by presumptive assay. Of those, $85.4 \%$ (76/89) were further confirmed to be ESBL producers by the double disk method. Given the high level of MDR detected for E. coli, we also screened $E$. coli isolates for the production of ESBLs. We determined that $62.2 \%(56 / 90)$ of them were ESBL producers by presumptive assay and $75 \%(42 / 56)$ were positive by double disk method.

Among Gram-positive organisms, 62\% (150/242) of $S$. aureus isolates were methicillin resistant and 3 of $35 \mathrm{E}$. faecium isolates were found to be VAN resistant. All of these isolates also typed positive for the vanA gene. None of the $S$. aureus isolates were resistant to VAN.

\section{Discussion}

In the hospital setting, different bacterial species may be the causative agents of infectious diseases. Due to their high level of pervasiveness and association with antimi- 


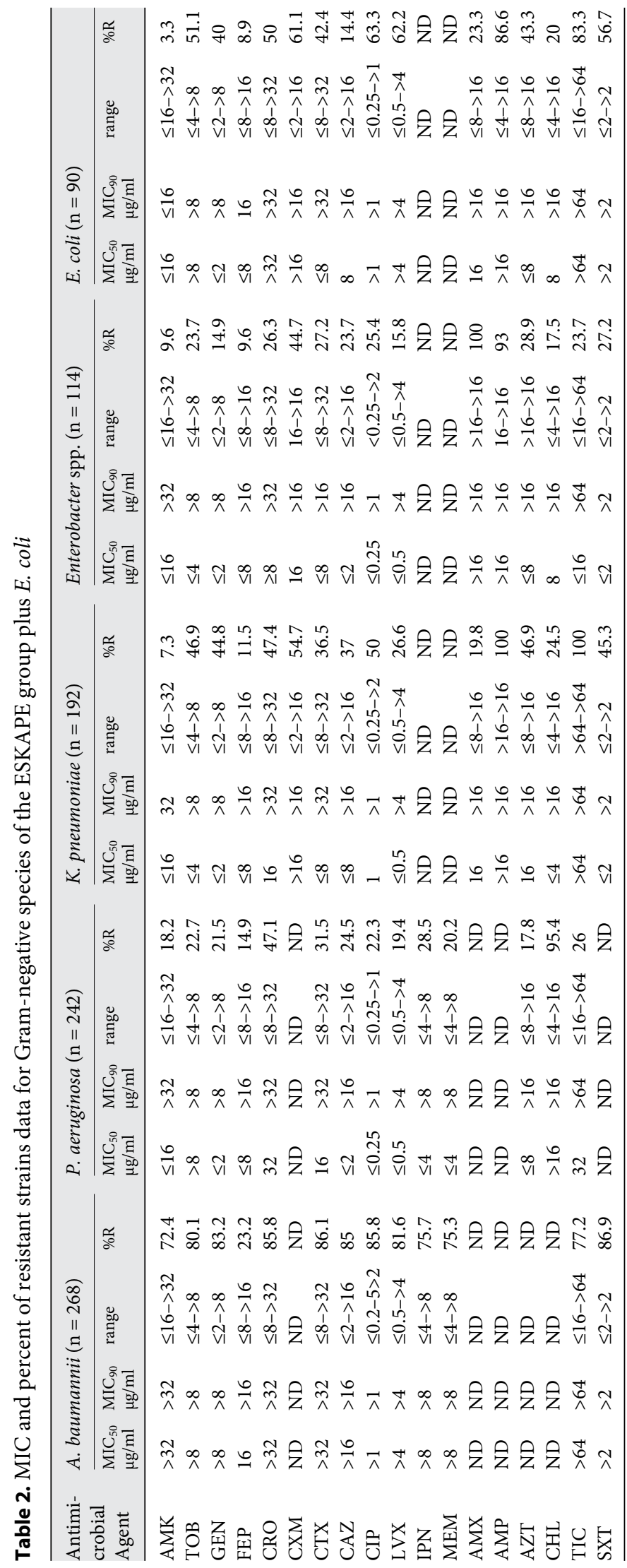

crobial resistance, the ESKAPE group of pathogens deserves particular attention. To control the incidence of infections due to ESKAPE pathogens, site-by-site surveillance studies are necessary to establish hospital-specific guidelines for effective empirical therapy [22]. In this study, we report a 1-year surveillance of ESKAPE pathogens and describe the incidence of ESBL-producing $K$. pneumoniae, of MRSA and of the presence of VAN-resistant E. faecium isolates in an ICU of a Mexican tertiary care teaching hospital.

The organisms most frequently recovered from our ICU were ESKAPE pathogens $(64.5 \%, 1,092 / 1,692)$, with a predominance of Gram-negative bacteria. The most common ESKAPE organisms were A. baumannii, $P$. aeruginosa and $K$. pneumoniae. These common bacterial pathogens were found to be similar to other prevalent pathogens reported in other countries $[1,8]$.

In general, a high MDR was observed for A. baumannii and $P$. aeruginosa. E. coli deserves special attention because it also showed a high level of MDR (76.7\%), even though this bacterial species is not included within the ESKAPE group. It seems that, for our hospital, surveillance monitoring should include E. coli. As such, it could be added to the ESKAPE group, thus forming a new acronym: ESKAPEE. In this hospital, the MDR ESKAPE pathogens were responsible for a considerable number of infections and represented the majority of isolates for which resistance to multiple antimicrobial agents reduces therapeutic alternatives for physicians.

A. baumannii was the most commonly isolated species in our ICU (15.8\%). In recent years, A. baumannii has emerged with an extensive antibiotic resistance spectrum [23]. In our study, $20.9 \%$ of $A$. baumannii were detected to be pan resistant to the antimicrobial agents evaluated. The alternative therapeutics that could be used include tigecycline or colistin; however, these antibiotics were not evaluated in this study.

A regional difference in A. baumannii resistance to carbapenems has been reported with resistance rates ranging from 3 to $59 \%$ [24-26]. The surveillance data presented in this study showed that $75.3 \%$ of $A$. baumannii clinical isolates were resistant to MEM. This value is greater than that previously reported for this hospital by our group (59\%) [11], which suggests a potential selection

Footnote to Table 2

$\% \mathrm{R}=$ Percent of resistant strains; $\mathrm{ND}=$ not determined. 
Table 3. MIC and percent of resistant strains data for Gram-positive species of the ESKAPE group

\begin{tabular}{|c|c|c|c|c|c|c|c|c|}
\hline \multirow{2}{*}{$\begin{array}{l}\text { Antimicrobial } \\
\text { agent }\end{array}$} & \multicolumn{4}{|c|}{ S. aureus $(\mathrm{n}=242)$} & \multicolumn{4}{|c|}{ Enterococcus spp. $(\mathrm{n}=156)$} \\
\hline & $\begin{array}{l}\mathrm{MIC}_{50} \\
\mu \mathrm{g} / \mathrm{ml}\end{array}$ & $\begin{array}{l}\mathrm{MIC}_{90} \\
\mu \mathrm{g} / \mathrm{ml}\end{array}$ & range & $\% \mathrm{R}$ & $\begin{array}{l}\mathrm{MIC}_{50} \\
\mu \mathrm{g} / \mathrm{ml}\end{array}$ & $\begin{array}{l}\mathrm{MIC}_{90} \\
\mu \mathrm{g} / \mathrm{ml} \\
\end{array}$ & range & $\% \mathrm{R}$ \\
\hline AMX & $>16$ & $>16$ & $\leq 4->16$ & 62.4 & ND & ND & ND & ND \\
\hline AMP & $\geq 0.25$ & $>0.25$ & $\leq 0.25->0.25$ & 90 & ND & ND & ND & ND \\
\hline OXA & $>4$ & $>4$ & $\leq 0.5->4$ & 61.9 & ND & ND & ND & ND \\
\hline PEN & $>0.25$ & $>0.25$ & $\leq 0.25->0.25$ & 89.3 & ND & $\mathrm{ND}$ & ND & ND \\
\hline ST1000 & ND & ND & ND & ND & $\leq 1,000$ & $>1,000$ & $\leq 1,000->1,000$ & 49.3 \\
\hline FEP & $>16$ & $>16$ & $\leq 8->16$ & 63.6 & ND & ND & ND & ND \\
\hline $\mathrm{CRO}$ & $>64$ & $>64$ & $\leq 8->64$ & 62.0 & ND & ND & ND & $\mathrm{ND}$ \\
\hline CXM & $>16$ & $>16$ & $\leq 4->16$ & 50.0 & ND & ND & ND & ND \\
\hline CLI & $>2$ & $>2$ & $\leq 0.5->2$ & 74.8 & ND & ND & ND & $\mathrm{ND}$ \\
\hline ERY & $>4$ & $>4$ & $\leq 0.5->4$ & 76.9 & $>4$ & $>4$ & $\leq 0.25->4$ & 75.6 \\
\hline GEN500 & ND & ND & ND & ND & $>500$ & $>500$ & $\leq 500->500$ & 51.9 \\
\hline LVX & $>2$ & $>2$ & $\leq 1->2$ & 53.3 & ND & ND & $\mathrm{ND}$ & ND \\
\hline LNZ & $\leq 2$ & $\leq 2$ & $\leq 2->4$ & 0.8 & $\leq 2$ & $\leq 2$ & $\leq 2->4$ & 3.8 \\
\hline QUD & $\leq 1$ & 2 & $\leq 1->2$ & 4.9 & $>2$ & $>2$ & $\leq 1->2$ & 75 \\
\hline TEI & $\leq 8$ & $\leq 8$ & $\leq 8->16$ & 4.9 & $\leq 8$ & $>16$ & $\leq 8->16$ & 10.2 \\
\hline TET & $\leq 2$ & 8 & $\leq 2->16$ & 9.5 & $>8$ & $>8$ & $\leq 2->8$ & 56.4 \\
\hline SXT & $\leq 2$ & $>2$ & $\leq 2->2$ & 12.4 & ND & ND & ND & ND \\
\hline VAN & 2 & 2 & $\leq 1->16$ & 4.5 & 2 & $>16$ & $\leq 1->16$ & 10.2 \\
\hline
\end{tabular}

$\% \mathrm{R}=$ Percent of resistant strains; $\mathrm{ND}=$ not determined.

for MEM-resistant strains. Of note, the previous study we refer to was performed in all hospital wards, while this study was restricted to only two ICUs.

ESBL-producing strains have been reported around the world in different genera of the Enterobacteriaceae family and have been isolated from different clinical specimens [27-30]. In this study, $39.6 \%$ of K. pneumoniae isolates were found to be ESBL producers. Higher values were detected for E. coli, as $46.7 \%$ of isolates were ESBL positive. This finding supports the importance of monitoring E. coli strains at this particular site. Of interest, the ESBL type has been previously studied within our hospital. For E. coli the dominant type was CTX-M-15 (66.7\%), and for K. pneumoniae the dominant type was SHV-12 $(51.5 \%)$ [31]. There was also an important clonal relatedness among K. pneumoniae ESBL isolates [30].The spread of ESBLs in hospitals is an important challenge for clinicians, as the therapeutic options for these organisms are limited. Additionally, infections attributed to ESBL-producing E. coli and K. pneumoniae are associated with increased mortality, length of hospital stay and increased cost [29].

The most common Gram-positive organism recovered from our ICUs was $S$. aureus. Among these isolates, MRSA made up $62 \%$ of all $S$. aureus isolates. This rate is higher than that reported in the USA (55\%), Canada (22.3\%) and Europe (ranging between $>1$ and 24\%), but lower than values observed in Turkey $(75 \%)[15,16,32$, 33].

Different types of potentially influential genes have been reported in VAN-resistant isolates. In a wide variety of enterococcal species, the $v a n A$ genotype is associated with a high level of resistance, the $v a n B$, vanB2 and $v a n D$ genotype with a moderate to high level of resistance, and the $\operatorname{van} C(C 1, C 2, C 3)$ with an intrinsically low level of resistance $[17,34]$. Accordingly, in this study, three $E$. faecium isolates were VAN-resistant and were also typed for the $v a n A$ gene. There is only one previous report of the presence of VAN-resistant E. faecium isolates in Mexico that were also typed for the vanA gene [35]. Our results highlight the presence of a high-level resistance to VAN in Mexico. Over the past few years, our ICUs have predominately used IPN and VAN for the treatment of many complicated infections, including ventilator-associated pneumonia, central line-associated bloodstream infections and many complicated intra-abdominal infections. This fact may explain, at least in part, the high level of drug resistance observed.

One weakness of this study is that we used the commercial methodology of Sensititre, which includes a range 
of concentrations that sometimes does not allow one to detect the exact MIC. Nonetheless, as the purpose of this study is to assess resistant strains, the testing of concentrations around each breakpoint was deemed acceptable and the data were analyzed with the knowledge of this bias.
The high rate of antibiotic resistance in our ICU underlines the urgent need for strategies for the prevention and control of infections caused by the ESKAPE pathogens. The results of this study will help us to implement an appropriate infection control of these highly resistant species.

\section{References}

1 Gould I: The epidemiology of antibiotic resistance. Int J Antimicrob Agents 2008; 32(suppl 1):S2-S9.

$>2$ Wienke M, Pfeifer Y, Weissgerber P, Marschal M, Autenrieth IB, Grobner S: In vitro activity of tigecycline and molecular characterization of extended-spectrum beta-lactamase-producing Escherichia coli and Klebsiella pneumoniae isolates from a university hospital in South-Western Germany. Chemotherapy 2012;58:241-248.

$>3$ Koksal F, Ak K, Kucukbasmaci O, Samasti M: Prevalence and antimicrobial resistance patterns of extended-spectrum beta-lactamaseproducing Escherichia coli and Klebsiella pneumoniae isolated from blood cultures in an Istanbul university hospital. Chemotherapy $2009 ; 55: 293-297$.

$>4$ Bassetti M, Ginocchio F, Mikulska M: New treatment options against Gram-negative organisms. Crit Care 2011;15:215.

5 Rice LB: Federal funding for the study of antimicrobial resistance in nosocomial pathogens: No ESKAPE. J Infect Dis 2008;197: 1079-1081.

$\checkmark 6$ Rice LB: Progress and challenges in implementing the research on ESKAPE pathogens. Infect Control Hosp Epidemiol 2010; 31(suppl 1):S7-S10.

7 Slama T: Gram-negative antibiotic resistance: there is a price to pay. Crit Care 2008; 12(suppl 4):S4.

$>8$ Kunz AN, Brook I: Emerging resistant Gramnegative aerobic bacilli in hospital-acquired infections. Chemotherapy 2010;56:492-500.

$>9$ Peleg A, Seifert H, Paterson D: Acinetobacter baumannii: emergence of a successful pathogen. Clin Microbiol Rev 2008;21:538-582.

$>10$ Rhomberg P, Jones R, Sader H, Fritsche T: Antimicrobial resistance rates and clonality results from the Meropenem Yearly Susceptibility Test Information Collection (MYSTIC) programme: report of year five (2003). Diagn Microbiol Infect Dis 2004;49:273-281.

-11 Garza-Gonzalez E, Llaca-Diaz JM, BosquesPadilla FJ, Gonzalez GM: Prevalence of multidrug-resistant bacteria at a tertiary-care teaching hospital in Mexico: special focus on Acinetobacter baumannii. Chemotherapy 2010;56:275-279.
12 Paterson D, Bonomo R: Extended-spectrum beta-lactamases: a clinical update. Clin Microbiol Rev 2005;18:657-686.

13 Hawkey P: Molecular epidemiology of clinically significant antibiotic resistance genes. $\mathrm{Br}$ J Pharmacol 2008;153(suppl 1):S406-S413.

14 Schiappa DA, Hayden MK, Matushek MG, Hashemi FN, Sullivan J, Smith KY, Miyashiro D, Quinn JP, Weinstein RA, Trenholme GM: Ceftazidime-resistant Klebsiella pneumoniae and Escherichia coli bloodstream infection: a case-control and molecular epidemiologic investigation. J Infect Dis 1996;174:529-536.

15 Klevens RM, Morrison MA, Nadle J, Petit S, Gershman K, Ray S, Harrison LH, Lynfield R, Dumyati G, Townes JM, Craig AS, Zell ER, Fosheim GE, McDougal LK, Carey RB, Fridkin SK, Investigators ABCsAM: Invasive methicillinresistant Staphylococcus aureus infections in the United States. JAMA 2007;298:1763-1771.

-16 de Kraker ME, Wolkewitz M, Davey PG, Koller W, Berger J, Nagler J, Icket C, Kalenic S, Horvatic J, Seifert H, Kaasch AJ, Paniara O, Argyropoulou A, Bompola M, Smyth E, Skally M, Raglio A, Dumpis U, Kelmere AM, Borg M, Xuereb D, Ghita MC, Noble M, Kolman J, Grabljevec S, Turner D, Lansbury L, Grundmann H, Group BS: Clinical impact of antimicrobial resistance in European hospitals: excess mortality and length of hospital stay related to methicillin-resistant Staphylococcus aureus bloodstream infections. Antimicrob Agents Chemother 2011;55:1598-1605.

17 Werner G, Coque TM, Hammerum AM, Hope R, Hryniewicz W, Johnson A, Klare I, Kristinsson $\mathrm{KG}$, Leclercq $\mathrm{R}$, Lester $\mathrm{CH}$, Lillie M, Novais C, Olsson-Liljequist B, Peixe LV, Sadowy E, Simonsen GS, Top J, VuopioVarkila J, Willems RJ, Witte W, Woodford N: Emergence and spread of vancomycin resistance among enterococci in Europe. Euro Surveill 2008;13:19046.

18 Deshpande LM, Fritsche TR, Moet GJ, Biedenbach DJ, Jones RN: Antimicrobial resistance and molecular epidemiology of vancomycin-resistant enterococci from North America and Europe: a report from the sentry antimicrobial surveillance program. Diagn Microbiol Infect Dis 2007;58:163-170.

19 Stamm W, Grayson ML, Nicolle L, Powell M: WHO Global Strategy for Containment of Antimicrobial Resistance. Geneva, World Health Organization, 2001.
20 Clinical and Laboratory Standards Institute: Performance Standards for Antimicrobial Susceptibility Testing: 20th Informational Supplement, M100-S20. Wayne, Clinical and Laboratory Standards Institute, 2010.

21 Clark NC, Cooksey RC, Hill BC, Swenson JM, Tenover FC: Characterization of glycopeptide-resistant enterococci from U.S. Hospitals. Antimicrob Agents Chemother 1993;37: 2311-2317.

22 Ramphal R: Importance of adequate initial antimicrobial therapy. Chemotherapy 2005; 51:171-176.

23 Cerqueira GM, Peleg AY: Insights into Acinetobacter baumannii pathogenicity. IUBMB Life 2011;63:1055-1060.

24 Al-Tawfiq J, Mohandhas T: Prevalence of antimicrobial resistance in Acinetobacter calcoaceticus-baumannii complex in a Saudi Arabian hospital. Infect Control Hosp Epidemiol 2007;28:870-872.

25 Gales A, Jones R, Forward K, Liñares J, Sader $\mathrm{H}$, Verhoef J: Emerging importance of multidrug-resistant Acinetobacter species and Stenotrophomonas maltophilia as pathogens in seriously ill patients: geographic patterns, epidemiological features, and trends in the SENTRY Antimicrobial Surveillance Program (1997-1999). Clin Infect Dis 2001;32(suppl 2):S104-S113.

26 Seifert H, Dowzicky M: A longitudinal analysis of antimicrobial susceptibility in clinical institutions in Germany as part of the tigecycline evaluation and surveillance trial (20042007). Chemotherapy 2009;55:241-252.

27 Diekema DJ, Pfaller MA, Jones RN, Doern GV, Kugler KC, Beach ML, Sader HS: Trends in antimicrobial susceptibility of bacterial pathogens isolated from patients with bloodstream infections in the USA, Canada and Latin America. SENTRY participants group. Int J Antimicrob Agents 2000;13:257-271.

28 Kang CI, Kim SH, Park WB, Lee KD, Kim $\mathrm{HB}$, Kim EC, Oh MD, Choe KW: Bloodstream infections due to extended-spectrum beta-lactamase-producing Escherichia coli and Klebsiella pneumoniae: risk factors for mortality and treatment outcome, with special emphasis on antimicrobial therapy. Antimicrob Agents Chemother 2004;48:45744581 . 
29 Tumbarello M, Sanguinetti M, Montuori E, Trecarichi EM, Posteraro B, Fiori B, Citton R, D’Inzeo T, Fadda G, Cauda R, Spanu T: Predictors of mortality in patients with bloodstream infections caused by extended-spectrum-beta-lactamase-producing Enterobacteriaceae: importance of inadequate initial antimicrobial treatment. Antimicrob Agents Chemother 2007;51:19871994.

-30 Muro S, Garza-González E, Camacho-Ortiz A, González GM, Llaca-Díaz JM, Bosques F, Rositas F: Risk factors associated with extendedspectrum $\beta$-lactamase-producing Enterobacteriaceae nosocomial bloodstream infections in a tertiary care hospital: a clinical and molecular analysis. Chemotherapy 2012;58:217-224.
31 Garza-Gonzalez E, Mendoza Ibarra SI, LlacaDiaz JM, Gonzalez GM: Molecular characterization and antimicrobial susceptibility of extended-spectrum $\beta$-lactamase-producing Enterobacteriaceae isolates at a tertiary-care centre in Monterrey, Mexico. J Med Microbiol 2011;60:84-90.

32 Stefani S, Varaldo P: Epidemiology of methicillin-resistant staphylococci in Europe. Clin Microbiol Infect 2003;9:1179-1186.
33 Alp E, Klaassen CH, Doganay M, Altoparlak U, Aydin K, Engin A, Kuzucu C, Ozakin C, Ozinel MA, Turhan O, Voss A: MRSA genotypes in Turkey: persistence over 10 years of a single clone of ST239. J Infect 2009;58:433-438.

34 Hegstad K, Mikalsen T, Coque TM, Werner G, Sundsfjord A: Mobile genetic elements and their contribution to the emergence of antimicrobial resistant Enterococcus faecalis and Enterococcus faecium. Clin Microbiol Infect 2010;16:541-554.

- 35 Cuellar-Rodríguez J, Galindo-Fraga A, Guevara $\mathrm{V}$, Pérez-Jiménez C, Espinosa-Aguilar L, Rolón AL, Hernández-Cruz A, López-Jácome E, Bobadilla-del-Valle M, Martínez-Gamboa A, Ponce-de-León A, Sifuentes-Osornio J: Vancomycin-resistant enterococci, Mexico City. Emerg Infect Dis 2007;13:798-799. 